\title{
Two Japanese Adverbials and Expressive Content
}

\author{
Eric McCready \\ University of Texas at Austin
}

\section{Introduction}

This paper considers the semantics and pragmatics of two Japanese adverbial expressions, yoku and yokumo, instances of which are shown in (1) and (2). 'PT' is used to gloss sentence-final particles here and in what follows.

(1) a. Yoku koko ni kita na!

YOKU here to came PT

'You came here, and I am surprised/happy that you did.'

b. Yoku ore o damasita na!

YOKU me ACC tricked PT

'You tricked me, and I am surprised you were able to.'

(2) a. Yokumo koko ni kita na!

YOKUMO here to came PT

'You have a lot of guts to come here!'

b. Yokumo ore o damasita na!

YOKUMO me ACC tricked PT

'I can't believe you had the gall to trick me.'

The purpose of the present paper is to describe the meaning, distribution, and felicity conditions of these adverbials, and to provide a formal account of them within a version of dynamic semantics.

\section{Meaning of yoku(mo)}

We can think of yoku and yoku(mo) as expressing the attitude of the speaker to the proposition $\varphi$ in their scope. Both express that $\varphi$ is surprising, but differ in that yoku expresses that the speaker feels positively about $\varphi$, while yokumo expresses that the speaker feels negatively about $\varphi$. Other subtle differences exist, as will be shown below.

It should be noted that other uses of yoku (but not yokumo) exist, on which it means 'often' or 'well,' as in (3a) and (3b) respectively. This pattern, in which a complex use of an adverbial is parasitic on a more extensional use, is common crosslinguistically. Waltereit (2001) cites German ja, which means 'yes' but also can be used as a modal particle, and eigentlich, which ordinarily means 'proper' but also has a use as a relevance-marking particle. The particle use of $j a$ will be discussed further in a later section.

(3) a. Taro ga yoku biiru o nomu

Taro NOM often beer ACC drinks

'Taro often drinks beer.'

R. Young (ed), SALT XIV 163-178, Ithaca, NY: Cornell University. 
b. Kono ronbun wa yoku dekita mon da ne. this paper TOP well done thing COP PT

'This paper is nicely done.'

In what follows, I will often write yoku(mo) to mean 'yoku and yokumo', where the two exhibit similar behavior.

\subsection{Characterizing the meaning of yoku(mo)}

I argue that the meaning of $y o k u(m o)$ is complex, and includes a statement of the speaker's attitude to the proposition in the adverbial's scope and location of that proposition on an exclamative-like scale of likelihood.

A first attempt at the compositional semantics of the two adverbials might look like this:

- $\llbracket y o k u \rrbracket=\lambda p \cdot[\operatorname{good}(p)]$

- $\llbracket y o k u m o \rrbracket=\lambda p \cdot[\operatorname{bad}(p)]$

This is not quite right, for a number of reasons. The first reason is that there is a crucial difference between yoku and yokumo: the former may express a general attitude, while the latter may not.

In the following example, use of yokumo indicates that the Kings' victory was bad for the speaker in some way, perhaps a lost bet. Yoku, conversely, simply expresses regard for the Kings' success. a. Kings-wa yoku Wolves-ni geemu-wan de kateta na
Kings-TOP YOKU Wolves-DAT game-one in could-win PT 'I'm amazed and pleased that the Kings beat the Wolves in Game 1.'

b. Kings-wa yokumo Wolves-ni geemu-wan de kateta na Kings-TOP YOKUMO Wolves-DAT game-one in could-win PT

'I'm shocked and personally inconvenienced by the fact that the Kings beat the Wolves in Game 1.'

Thus the semantics must express that the badness affected the speaker in the yokumo case. It is simple to modify the lexical entry for yokumo to reflect this difference. Here $\operatorname{bad}(s, p)$ should be read ' $p$ is bad for the speaker':

- $\llbracket y o k u m o \rrbracket=\lambda p \cdot[\operatorname{bad}(s, p)]$

However, these lexical entries still do not capture the full meaning of the adverbials, for two reasons. First, the meaning of the adverbials includes an element of shock or surprise that does not appear yet in the semantics. Second, there are complex issues with the deniability of sentences including yoku(mo). 


\subsection{Problem 1: Exclamatives}

I will claim that the semantics of $y o k u(m o)$ is related to that of exclamatives like the sentence in (5), and that the 'surprise' part of their meaning comes from this scalar component.

\section{(5) What a nice guy John is!}

Exclamative clauses have several properties related to yoku(mo) (Zanuttini and Portner, 2003): first, they are factive, and second, the proposition that is the denotation of the clause is located at the end of a pragmatically determined scale: often a scale of likelihood. Yoku(mo) does not seem to be factive in the standard sense, for reasons to be discussed below, although sentences including yoku(mo) do entail the truth of the modified proposition. However, the meaning of these adverbials does seem to have a scalar component.

I use the following scale, which is based on discussion of even in Guerzoni 2003. In words, $\varphi$ is more likely than $\psi$ in $w$ iff, given a contextually relevant set of facts, the likelihood of $\varphi$ is greater than that of $\psi$.

- $\varphi>_{L_{w}} \psi$ iff $\Gamma \models \operatorname{Likelihood}(\varphi)>\operatorname{Likelihood}(\psi)$, where $\Gamma$ is a set of contextually relevant facts in $w$.

Given this scale, we may revise the entries for yoku and yokumo as follows, where $C$ is a set of contextually relevant propositions which are also on the scale of likelihood. :

- $\llbracket y o k u \rrbracket=\lambda p \cdot\left[\operatorname{good}(p) \wedge \forall q \in C\left[(p \neq q) \rightarrow q>_{L_{w}} p\right]\right]$

- $\llbracket y o k u m o \rrbracket=\lambda p \cdot\left[\operatorname{bad}(s, p) \wedge \forall q \in C\left[(p \neq q) \rightarrow q>_{L_{w}} p\right]\right]$

These formulas state that $y o k u(m o)(\varphi)$ is true iff $\varphi$ is $\operatorname{good} / \mathbf{b a d}$ and is the least likely proposition in $w$ of some set of propositions, given a set of contextually relevant facts.

The denial problem will be addressed after the next section, in which I will set up some background.

\section{Particles and information states}

This section addresses the following observation: both yoku and yokumo require that the proposition to which they apply already be in the common ground. This fact can be seen clearly by attempting to use them in answers to questions (cf. Kratzer 1999), which must express new information from the perspective of the questioner (barring rhetorical questions). In this context, use of yoku(mo) is impossible.

(6) a. Context: A asks B 'Who did Austin marry?'

b. *Yoku Dallas to kekkon sita na! YOKU Dallas with marry did PT

'He did a really good and surprising thing by marrying Dallas!' 
(7) a. Context: A asks B 'Who did Austin marry?'

b. *Yokumo Dallas to kekkon sita na! YOKUMO Dallas with marry did PT

'He did an amazingly stupid and shocking thing by marrying Dallas!'

The badness of the examples above shows that yoku(mo) cannot simply be analyzed as factive, for if it could, the proposition in its scope could be accommodated in this situation; the question itself indicates A's willingness to accommodate.

However, it is perfectly possible to use yoku(mo) if the proposition it applies to is already in the common ground, as in (8). Here, since my friend is aware of his own actions, he already knows that he has drawn the picture in question.

(8) a. Situation: I go to a gallery where a painting by a friend of mine is being exhibited. I am surprised at the quality of his work. A few minutes later he shows up and I say:

b. omae-wa yoku konna e-o kaketa you-TOP YOKU this-kind-of picture-ACC could-draw

'I can't believe you could draw a picture this good.'

I model the requirement for hearer knowledge in a variant of a dynamic system developed by Asher and McCready (2004). In this system, information states are enriched to triples $\sigma=\left\langle s, \mathcal{E}_{\mathcal{S}}(s), \mathcal{E}_{\mathcal{H}}(s)\right\rangle$, where $\mathcal{E}$ is a function from subsets $s$ of $W$, the set of worlds, to epistemic possibilities, which are subsets of $\wp(W) . \mathcal{E}_{\mathcal{S}}$ represents the epistemic state of the speaker, $\mathcal{E}_{\mathcal{H}}$ that of the hearer. An epistemic state is taken to be the set of 'live' possibilities for the individual to which $\mathcal{E}$ is relativized. Which participant is speaker and which hearer switch with dialogue turns. I assume the existence of functions 1,2 and 3 that map respectively to the first, second, and third elements of the information state. The first element, $1(\sigma)$, is a model of the discourse itself, updated just as in standard DPL (Groenendijk and Stokhof, 1991) except that the elements are sets of worlds rather than world-assignment pairs. Since the topic of this paper does not involve anaphora, I have no need for assignments, and so leave them out to simplify the discussion; the semantics provided could easily be extended to include assignments should they be needed. $2(\sigma)$ is the set of possibilities that are 'live' for the speaker, while $3(\sigma)$ is made up of the possibilities that are 'live' for the hearer. Both $2(\sigma)$ and $3(\sigma)$ live on $1(\sigma)$, so the following entailments hold: $2(\sigma) \models 1(\sigma)$ and $3(\sigma) \vDash 1(\sigma)$.

Within this system, a given utterance can be associated with conditions on the ISs of speaker and hearer. In particular, the knowledge condition on yoku $(\mathrm{mo})$ can be characterized as follows:

- $\sigma+Y(\varphi)=\sigma^{\prime}$ if

- $\forall \epsilon \in 2(\sigma)[\epsilon+\varphi=\epsilon]$, and

- $\forall \epsilon \in 3(\sigma)[\epsilon+\varphi=\epsilon]$

else $\emptyset$. 
In words: for the update to be defined, all the speaker's epistemic possibilities must verify $\varphi$ and all the hearer's possibilities must also verify $\varphi$. Assuming mutual knowledge, the result is that $\varphi$ must be in the common ground.

What happens when it's not clear whether the hearer already knows $\varphi$ ? The condition above is not satisfied in this situation. It seems that, in this case, the sentence-final particle $n a$ is obligatory.

(9) When $\varphi=$ came_here $(j) \notin C G$ :

a. \# John yoku(mo) koko ni kita!

John YOKU(MO) here to came

'John was really good (had a lot of guts) to come here!'

b. John yoku(mo) koko ni kita na!

John YOKU(MO) here to came PT

'John was really good (had a lot of guts) to come here!'

Among many other uses (Moriyama, 2001; Noda, 2002), na can be used to emphasize and seek agreement on a statement.

(10) kinoo ame-ga ippai futta na

yesterday rain-NOM lots fell PT

'It rained a lot yesterday.'

Here, the speaker emphasizes his own belief that 'it rained a lot yesterday', and expresses the belief that the hearer is aware of this fact and agrees with his judgement about it. One way to understand this intuition is that use of the particle implies the speaker's certainty that $\varphi$ is true and that the hearer also believes so. We can characterize this idea as follows in our system (thanks to Kai von Fintel for helping clarify an error in an earlier version of this formula):

- $\llbracket n a \rrbracket=\lambda p \cdot N A(p)$

- $\sigma+N A(\varphi)=\langle 1(\sigma)+\varphi, 2(\sigma), 3(\sigma)+\varphi\rangle$ if:

$-2(\sigma)+\varphi=2(\sigma)$

- $2(\sigma)+\forall w^{\prime} \in \operatorname{Dox}_{H}(w)\left[\varphi\left(w^{\prime}\right)\right]=2(\sigma)$

- $\exists \epsilon \in 3(\sigma)[\epsilon+\varphi=\epsilon]$

else $\emptyset$.

On this analysis, $n a$ is eliminative just in case: the proposition in its scope is entailed by all the speaker's epistemic possibilities, the speaker believes that the proposition is true in all belief worlds of the hearer $\left(\operatorname{Dox}_{H}(w)\right.$, the set of worlds doxastically accessible to the hearer in $w$ ), and the hearer has not already rejected the proposition. Use of na thus expresses a stronger claim by the speaker than an ordinary assertion due to the constraints on its use. The strength of this claim leads to the emphatic quality of na-marked assertions, and the possibility of accommodation by the hearer. 


\section{Problem 2: Denial}

Having set the stage, we may now return to the lexical semantics of these adverbials. What happens when yoku(mo)+ $\varphi$ is denied? The above analysis predicts several possibilities, each corresponding to one bit of the semantics (see Faller 2002 for more on this 'denial test').

- Case 1: Hearer's information state does not actually support $\varphi$. Then the truth of $\varphi$ is denied.

- Case 2: Hearer's IS supports $\varphi$ but not $\operatorname{good} / \mathbf{b a d}(\varphi)$. Then the appropriateness of the attitude is denied.

- Case 3: Hearer's IS supports $\varphi$ and possibly $\operatorname{good} / \operatorname{bad}(\varphi)$, but not that $\varphi$ is unexpected. Then the unexpectedness is denied.

- Case 4: Hearer's IS supports $\varphi$ but neither of the other parts, which are then both denied.

The semantics provided above predicts that Case 1 is impossible, because $\varphi$ must already be in the hearer's IS for the sentence to be successfully processed, but that cases 2-4 are possible. Let us see whether these predictions are borne out.
A: Taro-ga yoku annani ii e-o kaketa na

Taro-NOM YOKU that-kind-of good picture-ACC could-draw PT

'I'm surprised and pleased that Taro could draw such a good picture.'
a. B: \#Uso da!
lie COP
'That's a lie!'
b. B: Tigau yo! wrong PT

'That's wrong!' $\Longrightarrow$ 'It's not that positive a fact.' OR 'It's not that surprising.'
c. B: sonna koto nai yo
that-kind-of thing COP.NEG PT

'That's not right.' $\Longrightarrow$ 'It's not that positive a fact.' OR 'It's not that surprising.'

(12) A: Taro-ga yokumo ano ko-o nagutta na

Taro-NOM YOKUMO that kid-ACC hit PT

'I'm surprised and shocked that Taro hit that kid.'

a. B: \#Uso da!

lie COP

'That's a lie!' 
b. B: Tigau yo!

wrong PT

'That's wrong!' $\Longrightarrow$ 'It's not that positive a fact.' OR 'It's not that surprising.'

c. B: Sonna koto nai yo!

that-kind-of thing COP.NEG PT

'That's not right.' $\Longrightarrow$ 'It's not that positive a fact.' OR 'It's not that surprising.'

As it turns out, Case 1 is indeed impossible. This is unsurprising: since $\varphi$ must be supported, it may not be denied felicitously. The analysis so far gets this right. Cases 2 and 3 are both possible. This is also predicted. Case 4 is impossible. This is surprising. Some modification seems necessary.

Before doing this modification, however, one may wonder why denial with uso 'lie' is impossible. I believe that the cause of this is just that A has privileged access to his own mental states (Mitchell, 1986), so B is able only to question the characterization, not to dispute its sincerity. (13) is bad for the same reason.
a. A: I'm cold.
b. B: \# That's a lie!

I will present a solution to the denial problem that makes crucial use of speech acts as related to discourse structure. This solution will be situated within Segmented Discourse Representation Theory (SDRT), a theory of discourse interpretation that enriches standard DRT with discourse relations that hold between speech act tokens (Asher and Lascarides, 2003). In SDRT, each speech act introduces an individual SDRS labelled with a speech act referent; this is written $\pi_{n}: \mathcal{K}_{n}$, where $\pi$ labels $\mathcal{K}$, which is an SDRS or a dynamic formula representing the content of an SDRS. Individual speech act tokens are integrated into a larger discourse structure with binary discourse relations $R$, so for all $\pi_{j}, R\left(\pi_{i}, \pi_{j}\right)$ for some $\pi_{i}$. R may be lexically determined or follow from inference.

I argue that yoku(mo) introduces a complex SDRS-condition (cf. the analysis of parentheticals in Asher 2000). The basic idea is that yoku(mo) has a complex meaning. On my analysis, it introduces into the discourse model three distinct propositions: the proposition $\varphi$ already assumed to be present in the ISs of speaker and hearer, a proposition that expresses the speaker's attitude toward $\varphi$ (generally bad), and a proposition that locates $\varphi$ on a scale of likelihood, just as discussed earlier. The difference from the earlier proposal is that each of these propositions is taken to be labeled with a distinct speech act referent; as with Asher's (2000) analysis of parentheticals, the effect of this move is that the content of the subordinate speech acts does not participate in relations with logical operators such as modals and conditionals, as needed for examples like (14). The speech act referents introduced by yoku $(\mathrm{mo})$ are then connected by underspecified discourse relations.

(14) a. If the party, an uninteresting social gathering, is over, then we should find somewhere else to get a drink.

(Asher 2000)

b. $\neq$ If the party is over and the party is an uninteresting social gathering, then we should find somewhere else to get a drink. 
This representation corresponds to the following SDRS-conditions. I ignore the speaker orientation of yokumo for simplicity.

$$
\begin{aligned}
& \pi_{1}: \varphi \\
& \pi_{2}: \operatorname{good} / \operatorname{bad}(\varphi) \\
& \pi_{3}: \forall \psi \in C\left[(\psi \neq \varphi) \rightarrow \psi>_{L_{w}} \varphi\right] \\
& \text { Commentary }\left(?, \pi_{2}\right) \\
& \text { Background }\left(?, \pi_{3}\right)
\end{aligned}
$$

\begin{tabular}{|c|}
\hline$\pi_{0}, \pi_{1}, \pi_{2}, \pi_{3}$ \\
\hline $\begin{array}{l}\pi_{1}: \varphi \\
\pi_{2}: \operatorname{good} / \operatorname{bad}(\varphi) \\
\pi_{3}: \forall \psi \in C\left[(\psi \neq \varphi) \rightarrow \psi>_{L_{w}} \varphi\right] \\
\text { Commentary }\left(\pi_{1}, \pi_{2}\right) \\
\text { Background }\left(\pi_{1}, \pi_{3}\right)\end{array}$ \\
\hline and \\
\hline$\pi_{0}, \pi_{1}, \pi_{2}, \pi_{3}$ \\
\hline $\begin{array}{l}\pi_{1}: \varphi \\
\pi_{2}: \operatorname{good} / \operatorname{bad}(\varphi) \\
\pi_{3}: \forall \psi \in C\left[(\psi \neq \varphi) \rightarrow \psi>_{L_{w}} \varphi\right] \\
\text { Background }\left(\pi_{1}, \pi_{3}\right) \\
\text { Commentary }\left(\pi_{1}, \pi_{2}\right)\end{array}$ \\
\hline
\end{tabular}

The attachment points of $\pi_{2}$ and $\pi_{3}$ are not set. I assume a constraint on attachment such that both $\pi_{2}$ and $\pi_{3}$ must attach to $\pi_{1}$. Crucially, however, the order in which they attach, is underspecified. This yields two possibilities:

Taking discourse relations to connect nodes, these representations correspond to the following graphs:

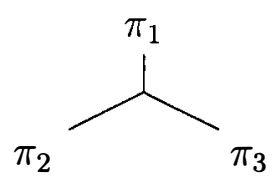

and

where Commentary $\left(\pi_{1}, \pi_{2}\right)$ and Background $\left(\pi_{1}, \pi_{3}\right)$.

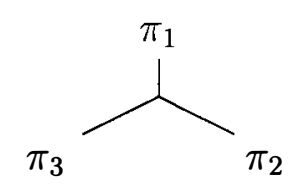

In SDRT, denial targets a single SDRS (Asher and Lascarides, 2003). The targeted SDRS must be on the right frontier of the discourse structure: $\pi$ is available only if it is the most recent utterance or lies on a path between the node representing it and the root of the graph. Given the structures above, it is only possible to target $\pi_{1}, \pi_{2}$, or $\pi_{3}$. Targeting $\pi_{2}$ with negation yields Case 2: denial of the attitude. Targeting $\pi_{3}$ yields Case 3: denial of surprisingness. It is also possible to target $\pi_{1}$. In SDRT, when an SDRS is denied, SDRSs that are connected to it with veridical subordinating relations are also denied; that is, denial is transitive through veridical relations. Veridical relations are those that fulfill the following condition: $R\left(\pi_{i}, \pi_{j}\right) \rightarrow \mathfrak{M}, i \models \mathcal{K}_{\pi_{i}} \wedge \mathcal{K}_{\pi_{j}} \wedge \phi_{R}$, where $\phi_{R}$ is the content introduced by the relation. Veridical relations thus are those relations that entail the truth of the two SDRSs they connect, as well as the truth of any additional content that comes from the relation itself. In SDRT, Commentary and Background are veridical relations. Therefore, if denial targets $\pi_{1}, \pi_{2}$ and $\pi_{3}$ in the structure above are also denied by 
transitivity. However, since $\pi_{1}$ is already supported by the input state, targeting it results in a contradiction and thus infelicity.

Interestingly, some speakers seem to allow denying the attitude and scalar content simultaneously. For such speakers, the condition requiring attachment to $\pi_{1}$ does not seem to hold. In this case, the range of attachment possibilities widens significantly, admitting the following structures:

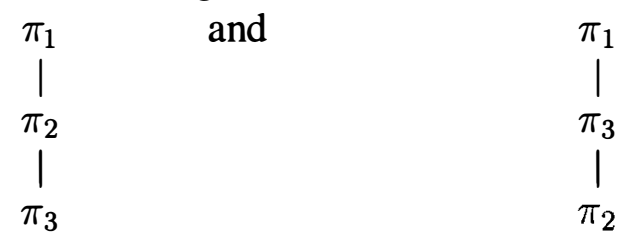

In the structure on the left, two possibilities exist for denials. Denial may either target $\pi_{3}$, in which case the surprisingness of the proposition is denied, or it may target $\pi_{2}$. In this second case, $\pi_{3}$ is also denied, by transitivity. The structure on the right admits a similar range of possibilities. The upshot is that, for these speakers, everything but the modified proposition itself $\left(\pi_{1}\right)$ may be denied simultaneously.

What happens when we add the sentence-final particle $n a$ to the SDRS? It must apply to the first proposition - that is, to the content of $\pi_{1}$, in order to ensure the right conditions on the input state. Thus, only the content of $\pi_{1}$ changes with the addition of $n a$, meaning that the following SDRSs can be constructed:

\begin{tabular}{|c|}
\hline$\pi_{0}, \pi_{1}, \pi_{2}, \pi_{3}$ \\
\hline$\pi_{1}: N A(\varphi)$ \\
\hline$\pi_{2}: \operatorname{good} / \operatorname{bad}(\varphi)$ \\
\hline$\pi_{3}: \forall \psi \in C\left[(\psi \neq \varphi) \rightarrow \psi>_{L_{w}} \varphi\right]$ \\
\hline $\operatorname{Commentary}\left(\pi_{1}, \pi_{2}\right)$ \\
\hline Background $\left(\pi_{1}, \pi_{3}\right)$ \\
\hline and \\
\hline$\pi_{0}, \pi_{1}, \pi_{2}, \pi_{3}$ \\
\hline$\pi_{1}: N A(\varphi)$ \\
\hline$\pi_{2}: \operatorname{good} / \operatorname{bad}(\varphi)$ \\
\hline$\pi_{3}: \forall \psi \in C\left[(\psi \neq \varphi) \rightarrow \psi>_{L_{w}} \varphi\right]$ \\
\hline Commentary $\left(\pi_{1}, \pi_{2}\right)$ \\
\hline Background $\left(\pi_{1}, \pi_{3}\right)$ \\
\hline
\end{tabular}

In the remainder of the paper I will use the earlier formalism when writing out lexical entries for $y o k u(m o)$ to enhance readability.

\subsection{German ja}

A number of researchers have examined the modal use of the German particle $j a$ from a semantic perspective in recent years (cf. Kratzer 1999; Potts 2003; Kaufmann 2004). As it turns out, ja and yoku( $\mathrm{mo}$ ) share a number of common properties. First, $j a$ also has requirements on hearer knowledge, and cannot be used as the answer to a question (Kratzer, 1999; Kaufmann, 2004).

(15) a. Context: A asks B 'Who did Austin marry?'

(Kratzer, 1999) 
b. *Austin hat ja Ashley geheiratet

Austin has JA Ashley married

'Austin married Ashley.'

Second, it appears that ja cannot be embedded under modals, which, as we will see shortly, is a property shared by yoku(mo):

(16) *Es ist moeglich, dass Hans ja einen neuen Hund hat.

it is possible that Hans JA a new dog has

'It is possible that Hans JA a new dog has.'

I will have little to say here about the correct analysis of $j a$, but will simply note that the analysis proposed by Kaufmann (2004) for the 'shared knowledge' requirement of $j a$ has much in common with mine. Kaufmann analyses $j a(\varphi)$ as presupposing $\varphi$ within a system of dynamic modal logic. The conditions on input information states I propose are ultimately quite similar. In principle, presuppositions can be accommodated, but Kaufmann shows that the particular presupposition he assumes (that of mutual knowledge) is difficult to accommodate, making predictions similar to my own. I leave the question of whether his system could also apply to $y o k u(m o)$ for future research.

\section{Distribution of yoku(mo)}

This section describes the distribution of these adverbials, which are extremely restricted. In short: $y o k u(m o)$ is very difficult to embed, and further may only apply to certain types of proposition. I argue that this difficulty stems from a restriction on yoku(mo): the sentence that it applies to must describe some actual past or current state of affairs. I will provide evidence for this claim from constructions with modals, conditionals, attitude verbs, and negation, showing that yoku(mo) is only possible in these cases when the sentence it applies to is coerced to a description of an actual eventuality, or, in the case of attitude verbs, when the sentence can be understood as quotative.

Modals: Neither yoku nor yokumo can appear with future-oriented modals $(17,18)$, either within their scope, as in (17a) and (18a), or scoping over them, as in (17b) and (18b). Note that although I use the possibility modal kamosirenai in these examples, the same facts hold for other sorts of future-oriented modals, such as the necessity modal nitigainai, although I omit the relevant examples here for space reasons. Pastoriented modals are possible, however, as shown by (19).

(17) a. *[Yoku koko ni kita] kamosirenai na! YOKU here to came might PT

'It is possible that you did really well to come here!'

b. *Yoku [koko ni kita kamosirenai] na! YOKU here to came might PT

'It is possible that you did really well to come here!' 
(18)

a. *[Yokumo koko ni kita] kamosirenai na! YOKUMO here to came might PT

'Maybe you have a lot of guts to come here!'

b. *Yokumo [koko ni kita kamosirenai] na! YOKUMO here to came might PT

'Maybe you have a lot of guts to come here!'

(19)

omae yokumo konna ii sakuhin dekita n ya na you YOKUMO this-kind-of good artwork was-able-to EMPH COP PT

'I can't believe you were able to make a piece this good!'

Why does this restriction exist? Two scopal possibilities exist for these sentences: $\operatorname{Modal}(\operatorname{Adv}(\varphi))$, where the modal scopes over the adverbial, or $\operatorname{Adv}(\operatorname{Modal}(\varphi))$, the opposite scoping. The first case is probably out for pragmatic reasons. Given the discussion in the previous section, the modal applies only to $\varphi$, not to the content of the adverbial, yielding $\operatorname{Modal}(\varphi)$. However, recall that the proposition yoku(mo) applies to must be already known to the hearer. Given this fact, asserting $\operatorname{Modal}(\varphi)$ would violate Gricean maxims and so be pragmatically odd.

This explanation, however, does not help in understanding why it is impossible to apply yoku $(\mathrm{mo})$ to $\operatorname{Modal}(\varphi)$, for this proposition could well still be informative. The reason this scoping is out is, I argue, that yoku $(\mathrm{mo})$ is lexically restricted so that it cannot be used to indicate one's attitude to situations that are not actually realized. Since future-oriented modalities by definition describe (possibly) unrealized situations, the scoping in question should be impossible if this hypothesis is correct Consider the following:

(*)Taro-ga yoku(mo) raigetu Tokyo ni iku na Taro-NOM YOKU(MO) next.month Tokyo to go PT

'It's surprising and good (bad) that Taro will go to Tokyo next month.'

If this sentence is interpreted as expressing an attitude toward Taro's trip to Tokyo (not Taro's decision to go to Tokyo next month), infelicity results. Similarly, if we interpret (b) to describe a general capacity rather than one that contributed to the success of a particular action, it is ungrammatical; (19) in fact does not describe an ability, but the actual fact of having painted a picture of high quality. I will call propositions that describe situations that have occurred in the actual world actual propositions.

Conditionals: $\operatorname{Yoku}(\mathrm{mo})$ is also impossible in conditionals: it may not apply to the antecedent or consequent ((a) and (b) for yoku, (a,b) for yokumo), or to the whole conditional.

a. *Yoku koko ni kitara, shachoo ga okoru daroo YOKU here to came-if, boss NOM get-angry probably

'If you do really well to come here, the boss will probably get angry.' 
b. *Taro ga sake o nomitakattara, yoku koko ni kuru daroo Taro NOM alcohol ACC want-drink-if, YOKU here to come probably 'If Taro wants to drink, he will be likely to do really well to come here.'

(22) a. *Yokumo koko ni kitara, shachoo ga okoru daroo YOKUMO here to came-if, boss NOM get-angry probably

'If you have a lot of guts to come here, the boss will probably get angry.'

b. *Taro ga sake o nomitakattara, yokumo koko ni kuru

Taro NOM alcohol ACC want-drink-if, YOKUMO here to come daroo probably

'If Taro wants to drink, he will probably have a lot of guts to come here.'

Given the discussion of the modal case, these facts are not unexpected. If $\varphi$ or $\psi$ are already known to be true, one should not assert $\varphi \rightarrow \psi$; thus the infelicity of applying yoku(mo) to conditional antecedent or consequent. And, if yoku(mo) requires that the proposition in its scope be actual, we can also explain why applying $y o k u(m o)$ to the whole conditional is bad too.

Negation: $\operatorname{Yoku}(\mathrm{mo})$ can appear under negation $(23,24)$. However, like the modal cases, in these cases the sentence seems to serve as a negative description of a positive event (cf. Miller 2003), as in (25). If this is correct, then negated sentences provide further evidence that $y o k u(m o)$ requires actual propositions.

a. Yoku koko ni konakatta na!

YOKU here to came PT

'You didn't come here, and I am surprised you were able not to.'

b. Yoku ore o damasanakatta na! YOKU me ACC tricked PT

'You didn't trick me, and I am surprised you forbore. (one reading)'

a. *Yokumo koko ni konakatta na! YOKUMO here to came-not PT

'You have a lot of guts to not come here!'

b. *Yokumo ore o damasanakatta na! YOKUMO me ACC not-tricked PT

'I can't believe you had the gall to not trick me.'

(25) John saw Mary not leave.

I characterize these facts formally by putting a condition on the type of proposition which can saturate the $\lambda$-term in the lexical entry of yoku $(m o)$ to the effect that the proposition must describe a situation whose temporal trace is located at a past time, or one that is ongoing at the present moment. The need for admitting situations that are still happening at the speech time is made clear by progressivized sentences like (26): 
(26)

Omae-ga yoku(mo)
you-NOM
YOKU(MO) this.kind.of thing-ACC do-PROG NA

'I'm surprised you are able to (have the guts do) be doing this kind of thing.'

The condition is implemented in the form of a presupposition (the formula contained within braces in the lexical entries below). Effectively, this condition selects for the set of actual propositions. The final lexical entries for yoku and yokumo are then as follows, where the predicate $\operatorname{Desc}(e, \varphi)$ is true iff $\varphi$ describes the eventuality $e$ :

- $\llbracket y o k u \rrbracket=\lambda p\left\{\exists e\left[\tau(e)=t \wedge t \leq n \wedge \operatorname{Desc}(e, p) \wedge p\left(w_{0}\right)\right]\right\} \cdot[\operatorname{good}(p) \wedge \forall q \in$ $\left.C\left[(q \neq p) \rightarrow q>_{L_{w}} p\right]\right]$

- $\llbracket$ yokumo $\rrbracket=\lambda p\left\{\exists e\left[\tau(e)=t \wedge t \leq n \wedge \operatorname{Desc}(e, p) \wedge p\left(w_{0}\right)\right]\right\} .[\operatorname{bad}(s, p) \wedge \forall q \in$ $\left.C\left[(q \neq p) \rightarrow q>_{L_{w}} p\right]\right]$

Use of these adverbials now presupposes that $\exists e[\tau(e)=t \wedge t \leq n]$; that there be an eventuality that took place either in the past or at the present moment $n . \tau$ in this formula is the temporal trace function that returns the runtime of an eventuality. The additional condition $p\left(w_{0}\right)$ additionally requires the proposition to hold in the actual world, and so forces the eventuality to have taken place there.

Attitudes: $Y o k u(m o)$ cannot be embedded under attitudes in the general case. The sentences below are ungrammatical when yoku/yokumo modifies the proposition that is the object of the attitude.

a. $\quad$ [Yoku(mo) koko ni kita na] to sinzita
YOKU(MO) here to came PT COMP believed

'(You) believed I was really good (bad) to come here.'

b. *[Yoku(mo) koko ni kita] to sinzita na! YOKU(MO) here to came COMP believed PT

'(You) believed I was really good (bad) to come here.'

They are fine, however, when the object modified by the adverbial is the proposition that such-and-such was believed. (ba), for instance, is acceptable on the interpretation 'You were good to believe that I came here!' Here, yoku(mo) modifies the entire sentence, and hence the actual proposition that describes the act of believing.

Why is modification of the embedded sentence impossible? There are several possibilities. One is that the proposition modified by yoku(mo) must be asserted. If this is correct, we can see why modifying the embedded sentence is impossible: asserting $\operatorname{Att}(x, \varphi)$ does not entail the assertion of $\varphi$. A second possibility is that yoku $(m o)$ is tied to root clauses, and so cannot apply to embedded sentences except under very special circumstances. (This suggestion is due to Pranav Anand.) In the end I will reject both of these possibilities, however, showing that this restriction, like those observed above, follows directly from the actuality condition on propositions modified by yoku(mo).

One way to decide between the possibilities is to examine sentences that lack assertive force, such as questions and imperatives. In these contexts, (at least some) 
root phenomena are permitted, but since no assertive force is present, elements requiring assertion are not. As the examples below show, yoku(mo) is impossible in questions and imperatives, which makes the assertion-based analysis appear to be the correct one.

$$
\begin{aligned}
& \text { a. *Taro-ga yoku(mo) ano ko-o nagutta no ka? } \\
& \text { Taro-NOM YOKU(MO) that kid-ACC hit EMPH PT } \\
& \text { 'Was Taro good (bad) to hit that kid?' (bad unless echo question) } \\
& \text { b. *yokumo sara-o arattekoi! } \\
& \text { YOKUMO plate-ACC wash-come-IMP }
\end{aligned}
$$

'Go wash the plates and surprise and inconvenience me by doing so!'

Before concluding that assertion is necessary for use of yoku(mo), however, we should consider again the actuality condition introduced above. There, I required that the proposition yoku(mo) applies to describe a proposition that describes a situation temporally located in the past or overlapping the present, in the actual world. Crucially, complements of attitude verbs do not have this property. Attitude verbs describe what holds in the belief worlds of the speaker (in the case of sinziru 'believe'); thus, although the proposition may describe a past eventuality, it is not actual in the necessary way. Therefore, the condition on actuality of propositions is sufficient to derive the impossibility of using yoku( $\mathrm{mo})$ in attitude objects as well.

Quotatives: $Y o k u(m o)$ can be embedded under attitude verbs just in case that verb can be construed as quotative, as in (29).
a. $\quad$ Yoku(mo) koko ni kita] to omotta na!
YOKU(MO) here to came COMP thought PT
'(You) thought (I) did a good (bad) thing to come here!'
b. [Yoku(mo) ore o damasita] to omotta na! YOKU(MO) me ACC tricked COMP thought PT

'(I) thought you did a good (bad) thing to trick me.'

For these examples to be grammatical, we have to construe my thought as having had the form expressed by the sentential complement. In the case of quoted thoughts, standard semantic restrictions and interactions do not apply, as shown by many authors (see e.g. Schlenker 2003 for discussion). For this reason, the grammaticality of examples like these does not constitute a genuine counterexample to the generalizations made here. That these sentences are quotative can be verified by including indexicals in the complement, as in (30); ore is a masculine, low-register first person pronoun that sounds natural with yoku(mo), both of which are low-register and tend to be associated with masculine or rough speech.

(30) Indexicals in complement:

a. John-wa [ore-ga yoku(mo) koko ni kita] to omotta na! John-TOP I-NOM YOKU(MO) here to came COMP thought PT 'John thought he did a good (bad) thing to come here!' NOT 'John thought that I did a good (bad) thing ...' 
b. John-wa [yoku(mo) ore o damasita] to omotta na! John-TOP YOKU(MO) me ACC tricked COMP thought PT

' $\mathrm{John}_{i}$ thought (he) did a good (bad) thing to trick me $\mathrm{m}_{i}$ ' NOT 'John thought that (he) did a good (bad) thing to trick the speaker'

I should note that there may be additional restrictions (on, for instance, intentionality, agentivity, and disjunction), but speaker judgements are inconsistent, and so I do not consider these issues here.

\section{Conclusions}

I have shown in this paper that yoku $(m o)$ requires prior knowledge or a discourse particle to be felicitously used. When felicitous, it expresses a speaker attitude to the proposition it applies to, and states that it is unexpected. I modelled these facts in a dynamic semantics incorporating elements from SDRT. I further showed that yoku(mo) can apply only to propositions that describe events that have taken place in the actual world.

I would like to close with a final comment. The meanings given for yoku(mo) can switch polarity in certain contexts; the positive meaning of yoku can become negative, as in (31a), and the negative attitude expressed by yokumo can become positive, as in (31b), repeated from (19).

$$
\begin{aligned}
& \text { a. omae yoku ano ii ko-o naguru ki-ni natta na } \\
& \text { you YOKU that good kid-ACC hit feeling became PT } \\
& \text { 'I'm shocked at you for deciding to hit that kid.' }
\end{aligned}
$$

b. omae yokumo konna ii sakuhin dekita n ya na you YOKUMO this-kind-of good artwork was-able-to EMPH COP PT 'I can't believe you were able to make a piece this good!'

The positive/negative meanings of these expressions are probably best regarded as defaults which can be overriden by pragmatic information. For instance, the polarity switching of yokumo in (b) presumably comes about because there is ordinarily nothing negative about being able to produce good artwork. Similar facts have been noted by Potts (2003) with respect to epithets. The switching may also be related to intonational contour.

\section{Acknowledgements}

Thanks to Nicholas Asher, Rajesh Bhatt, Makiko Irie, Alexis Palmer, Brian Reese, Bernhard Schwarz, Junko Shimoyama, Linton Wang and audiences at the UT Logic and Semantics Group, SALT XIV (especially Pranav Anand, Anastasia Giannikidou, Chris Potts, and Kai von Fintel), and Osaka University for useful discussions. Thanks also to Hitoshi Horiuchi, Midori Morita, Junko Nakajima, Norihiro Ogata and Tomoko Sakuma for help with judgements. 


\section{References}

Asher, Nicholas. 2000. Truth conditional discourse semantics for parentheticals. Journal of Semantics 17:31-50.

Asher, Nicholas and Alex Lascarides. 2003. Logics of Conversation. Cambridge University Press.

Asher, Nicholas and Eric McCready. 2004. Were, would, must and a compositional account of counterfactuals. Paper presented at the 2004 Meeting of the Society for Exact Philosophy.

Faller, Martina. 2002. Semantics and Pragmatics of Evidentials in Cuzco Quechua. Ph.D. thesis, Stanford University.

Groenendijk, Jeroen and Martin Stokhof. 1991. Dynamic predicate logic. Linguistics and Philosophy 14:39-100.

Guerzoni, Elena. 2003. Why Even Ask?. Ph.D. thesis, MIT. Draft of July 2003.

Kaufmann, Stefan. 2004. A modal analysis of expressive meaning: German ja under quantifiers. Handout of talk presented at Kobe Shoin.

Kratzer, Angelika. 1999. Beyond ouch and oops: How descriptive and expressive meaning interact. Available from Semantics Archive.

Miller, Phillip. 2003. Negative complements in direct perception reports. In Proceedings of Chicago Linguistics Society 39.

Mitchell, Jonathan. 1986. The Formal Semantics of Point of View. Ph.D. thesis, University of Massachusetts at Amherst.

Moriyama, Yoshiyuki. 2001. Syuuzyosi 'ne' no intoneesyun [The intonation of the sentence-final particle 'ne']. In Bunpoo to Onsei III [Grammar and Phonology III]. Kurosio Press.

Noda, Harumi. 2002. Syuuzyosi no kinoo [The functions of sentence-final particles]. In Modariti [Modality]. Kurosio Press.

Potts, Christopher. 2003. The Logic of Conventional Implicatures. Ph.D. thesis, University of California at Santa Cruz. To appear from Oxford University Press.

Schlenker, Philippe. 2003. A plea for monsters. Linguistics and Philosophy 26:29_ 120.

Waltereit, Richard. 2001. Modal particles and their functional correlates: a speechact theoretic approach. Journal of Pragmatics 33:1391-1417.

Zanuttini, Raffaella and Paul Portner. 2003. Exclamative clauses at the syntaxsemantics interface. Language 79(1):39-81. 